\title{
The GARP Domain of the Rod CNG Channel's $\beta 1$-subunit Contains Distinct Sites for Outer Segment Targeting and Connecting to the Photoreceptor Disc Rim
}

Jillian N. Pearring ${ }^{1,2, \#}$, Jason R. Willer ${ }^{1,2}$, Jorge Y. Martínez-Márquez ${ }^{1,2}$, Eric C. Lieu ${ }^{3}$, Raquel Y. Salinas ${ }^{3,{ }^{*}}$ and Vadim Y. Arshavsky ${ }^{3}$

Departments of Ophthalmology ${ }^{1}$ and Cell and Developmental Biology ${ }^{2}$, University of Michigan, Ann Arbor, MI, 48105, USA

Albert Eye Research Institute ${ }^{3}$, Duke University, Durham, NC, 27710, USA

* Current Institute: MD Anderson Cancer Center, University of Texas, Houston, TX, 77030, USA

\# Correspondence: pearring@umich.edu

Abbreviated title: Rod outer segment targeting of the CNG channel

Key words: Photoreceptor, cyclic nucleotide-gated channel, traffic, outer segment, cilium Pages:

Number of figures: 7 , tables: 1

Number of words for abstract: 196, introduction: 648, results: 2201 and discussion: 927.

Acknowledgements: This work was supported by the NIH grants EY025732 (JNP), EY012859 (VYA), EY030451 (VYA), EY007003 (University of Michigan), EY005722 (Duke University), Matilda E. Ziegler Research Award (JNP) and Research to Prevent Blindness.

Conflict of Interest Statement: The authors declare no competing financial interests. 


\begin{abstract}
Vision begins when light is captured by the outer segment organelle of photoreceptor cells in the retina. Outer segments are modified cilia filled with hundreds of flattened disc-shaped membranes. Disc membranes are separated from the surrounding plasma membrane and each membrane type has unique protein components. The mechanisms underlying this protein sorting remain entirely unknown. In this study, we investigated the outer segment delivery of the rod cyclic nucleotide-gated (CNG) channel, which is located in the outer segment plasma membrane where it mediates the electrical response to light. We now show that the targeted delivery of the CNG channel to the outer segment requires pre-assembly of its constituent $\alpha 1$ and $\beta 1$ subunits and that CNG $\beta 1$ contains specific targeting information encoded within the glutamic acid-rich region of its N-terminal GARP domain. We also found that the GARP domain connects the CNG channel to photoreceptor disc rims likely through an interaction with peripherin-2 and demonstrated that this function is performed by a proline-enriched region adjacent to the GARP domain. Our data reveal fine functional specializations within the structural domains of the CNG channel and suggest that channel delivery to the outer segment is independent of peripherin-2 interactions.
\end{abstract}




\section{Significance Statement}

The precise delivery and organization of signaling proteins in the ciliary outer segment organelle of photoreceptor cells is critical for light detection. We report that the CNG channel, mediating the electrical response to light in rods, contains a region within the N-terminus of its CNG 1 subunit that encodes the outer segment targeting information for the entire channel. This targeting region is adjacent to a region that connects $C N G \beta 1$ to the rims of photoreceptor discs, likely determining the subcellular compartmentalization of the CNG channel into the outer segment plasma membrane.

\section{Introduction}

Photoreceptor cells of the retina are responsible for light detection. They contain a modified primary cilium, called the outer segment, which houses all the molecular components necessary for capturing light and eliciting an electrical response. To increase light sensitivity, outer segments contain a stack of flattened membrane "discs", so that incoming photons pass through hundreds of membrane surfaces packed with the visual pigment, rhodopsin. Another unique outer segment feature is that it undergoes constant regeneration, which places a heavy demand on the trafficking of signaling and structural proteins to this compartment (Pearring et al., 2013; Goldberg et al., 2016; Spencer et al., 2020b). Defects in these trafficking mechanisms underlie many forms of inherited retinal degeneration, ultimately leading to blindness.

Within the outer segment, there is functional specialization between the membranes of photoreceptor discs and the surrounding plasma membrane. Whereas discs primarily harbor components of the visual signaling pathway (Molday and Molday, 1987; Skiba et al., 2013), the cyclic nucleotide-gated (CNG) channel required to elicit an electrical response to light and the $\mathrm{Na} / \mathrm{Ca}-\mathrm{K}$ exchanger regulating $\mathrm{Ca}^{2+}$ dynamics are confined to the plasma membrane (Bauer, 1988; Reid et al., 1990). Previous studies, focused primarily on disc-resident transmembrane proteins, showed that their outer segment trafficking relies on specific sequences for targeting. These proteins include rhodopsin (Sung et al., 1994), peripherin-2 (Tam et al., 2004; Salinas et al., 2013), RDH8 (Luo et al., 2004) and R9AP (Pearring et al., 2014). Two other proteins, GC-1 and PRCD, have been shown to be delivered to the outer segment in a complex with rhodopsin (Pearring et al., 2015; Spencer et al., 2016). Less is known about the outer segment delivery of plasma membrane-resident proteins and even less about their segregation specifically into this membrane. 
In this study, we investigated the outer segment targeting and plasma membrane sorting of the CNG channel. This channel is composed of four subunits: three $\alpha 1$ and one $\beta 1$ (Weitz et al., 2002; Zheng et al., 2002; Zhong et al., 2002). Early studies of CNG channel trafficking, performed by heterologously expressing its subunits in Xenopus oocytes, showed that both CNGa1 and the CNGa1/ CNGß1 complex, but not CNGß1 alone, are effectively delivered to the oocyte plasma membrane and form functional channels. Yet, only the channel formed by both subunits recapitulates electrical and gating properties of the native channel (Kaupp et al., 1989; Chen et al., 1993; Colville and Molday, 1996; Trudeau and Zagotta, 2002; Zheng et al., 2002). Transgenic expression of the channel in Xenopus rods showed that removing the N-terminal glutamic acid-rich protein (GARP) domain from CNG $\beta 1$ results in accumulation of the mutant subunit in the biosynthetic membranes and mistrafficking to the plasma membrane of the inner segment (Nemet et al., 2014), suggesting an important role for the GARP domain in CNG $\beta 1$ transport.

The CNG channel was reported to associate with the Na/Ca-K exchanger within the outer segment plasma membrane (Molday and Molday, 1998). In addition, the channel is connected to the photoreceptor disc rim through binding to a rim-specific protein, peripherin-2 (Poetsch et al., 2001; Conley et al., 2010). The latter interaction is believed to link the discs with the plasma membrane, likely stabilizing the disc stack within the outer segment.

We now demonstrate that the CNG channel travels through both the ER and Golgi on its route to the rod outer segment and that its specific outer segment delivery requires the channel's pre-assembly. This targeting is mediated by the glutamic acid-rich region of CNG $\beta 1$ 's GARP domain. Whereas this targeting region confers outer segment localization, it does not define specific plasma membrane localization. We observed that the adjacent R1-4 region of the GARP domain accumulates in disc incisures likely through peripherin-2 binding. Together, our results show that outer segment trafficking and peripherin-2 interaction are performed by two distinct sites within the CNG $\beta 1$ subunit's GARP domain and suggest that the plasma membrane sequestration of the channel relies on peripherin-2 interaction.

\section{Materials and Methods}

\section{Animals}

Mice were handled following the protocols approved by the Institutional Animal Care and Use Committees at the University of Michigan (registry number A3114-01) and Duke University 
(registry number A011-14-01). Albino WT CD1 mice used in electroporation experiments were obtained from Charles River. Cngb1-X1/- mice (Zhang et al 2011) used in Western blotting and electroporation experiments were kindly provided by Steven Pittler (University of Alabama). Pigmented wild-type C57BL/6J mice used for Western blotting were from Jackson Labs (Bar Harbor, ME). All mice were housed under a 12/12-hour light cycle. The experimenters were not blinded to genotype.

In vivo electroporation

Retinal transfection of neonatal mice by the in vivo electroporation technique (Matsuda and Cepko, 2007) was used with modifications described in (Pearring et al., 2015; Salinas et al., 2017) to express exogenous constructs in mouse rods. DNA constructs were electroporated into the retinas of wild-type CD1 or Cngb1-X1/- neonatal mice. Following anesthetization of neonatal mice (P0-P2) on ice, the eyelid and sclera were punctured at the periphery of the eye using a 30-gauge needle. A blunt-end 32-gauge needle was advanced through the puncture wound until reaching the subretinal space, and $0.3-0.5 \mu \mathrm{l}$ of concentrated plasmid DNA $(2 \mu \mathrm{g} / \mu \mathrm{l}$ of the construct of interest and $1 \mu \mathrm{g} / \mu \mathrm{l}$ soluble mCherry to visualize transfected cells) was deposited. A tweezer-type electrode (BTX) was placed over the mouse's head with the positive electrode overlying the injected eye. Five $100 \mathrm{~V}$ pulses of $50 \mathrm{~ms}$ duration were applied using an ECM830 square pulse generator (BTX). Neonates were returned to their mother and allowed to develop until postnatal day 21 when mice were sacrificed by $\mathrm{CO}_{2}$ inhalation followed by decapitation and retinal tissue was collected for analysis.

\section{Generation of transgenic tadpoles}

Transgenic Xenopus tadpoles were produced using restriction enzyme-mediated integration developed previously (Kroll and Amaya, 1996; Amaya and Kroll, 1999), with modifications described in (Batni et al., 2000; Whitaker and Knox, 2004).

\section{Primary antibodies}

The following antibodies were generously provided by: Robert Molday, University of British Columbia (mAb 1D1, anti-CNGa1; and mAb 8G8, anti-GARP); Steven Pittler, University of Alabama at Birmingham (pAb, anti-CNGß1); Gabriel Travis, University of California Los Angeles (pAb, anti-peripherin-2). The polyclonal antibody against Rom-1 was generated in the Arshavsky laboratory (Gospe et al., 2011). Rabbit antibody against R9AP sequence 144-223 is described in (Keresztes et al., 2003). Commercial antibodies were: mAb 1D4, anti-rhodopsin (Abcam, ab5417); pAb M-18, anti-ABCA4 (Santa Cruz, sc-21460); mAb anti-Na/K-ATPase 
(Santa Cruz, sc-58628); mAb M2, anti-FLAG (Sigma-Aldrich, F1804); pAb, anti-FLAG (SigmaAldrich, F7425); pAb, anti-GFP conjugated to Alexa Fluor 488 (Molecular Probes); and pAb, anti-MYC (Cell Signaling, 2278S).

\section{DNA Constructs}

DNA constructs were generated using standard PCR-based subcloning methods. Point mutations were generated using the QuikChange II XL kit (Stratagene). All DNA constructs were cloned between a 5' Agel and 3' Notl sites and sequence confirmed. For mouse in vivo electroporation, the pRho plasmid driving gene expression under the $2.2 \mathrm{~kb}$ bovine rhodopsin promoter was used (Addgene, plasmid \# 11156). For Xenopus transgenics, the XOP1.5 vector was used for constructs containing GFP, while untagged and Myc-tagged CNG $\beta 1$ constructs were expressed using a dual promoter strategy described in Baker et al. (2008). In brief, along with the Xenopus opsin promoter driving expression of the various CNG $\beta 1$ constructs in rods, a cassette containing the $\mathrm{Y}$-crystallin promoter was used to drive GFP expression in the lens. DNA templates were obtained as follows: human Cngb1 was a gift from Van Bennett (Duke University), mouse Cnga1 and Cngb1 were amplified from mouse retina cDNA (Stratagene, La Jolla, CA); the Myc epitope was added using overlap extension PCR. All chimeric constructs were produced using overlap extension PCR. All forward and reverse primers were designed to introduce 5'-Agel and 3'-Notl sites respectively. A complete list of primers can be found in Table 1.

\section{Immunofluorescence}

Xenopus retinal cross-sections: GFP expressing transgenic tadpoles at developmental stages 43-45 were anesthetized in $0.2 \%$ Tricaine, fixed in 4\% paraformaldehyde in PBS, cryoprotected in $30 \%$ sucrose, and frozen in OCT tissue freezing compound (Fisher). $12 \mu$ m-thick sections were cryosectioned for immunostaining. To detect human CNG $\beta 1$ or Myc-tagged constructs, tissue sections were permeabilized for 10 min with $0.1 \%$ Triton X-100 in PBS, blocked with $5 \%$ goat serum and $0.5 \%$ Triton $\mathrm{X}-100$ in PBS for 1 hour at $22^{\circ} \mathrm{C}$. Specific primary antibodies were diluted 1:2000 in blocking and incubated overnight at $4^{\circ} \mathrm{C}$. The next day, sections were rinsed in 0.5\% PBX and incubated with anti-mouse lgG secondary antibodies conjugated to Alexa Fluor 594 (Jackson ImmunoResearch) and 10 gg/ml Hoechst 33342 (Thermo Fisher Scientific, $\mathrm{H} 3569)$ in blocking solution for 2 hours at $22^{\circ} \mathrm{C}$. Slides were coverslipped using Immu-Mount (Thermo Fisher Scientific).

Mouse retinal cross-sections: Posterior eyecups were fixed for 1 hour in $4 \%$ paraformaldehyde in PBS, rinsed 3 times in PBS, and embedded in 7.0\% low melt agarose (Sigma, A3038). 100 
$\mu \mathrm{m}$ cross-sections through the central retina were collected using a vibratome (Leica VT1200S), placed in a 24-well plate, and blocked in 5\% goat serum and 0.5\% Triton X-100 in PBS for 1 hour at $22^{\circ} \mathrm{C}$. Sections were incubated in primary antibody diluted in blocking solution overnight at $4^{\circ} \mathrm{C}$, rinsed 3 times in PBS, and incubated with $10 \mu \mathrm{g} / \mathrm{ml}$ Hoechst 33342 and goat or donkey secondary antibodies conjugated with Alexa Fluor 488, 568, or 647 (Jackson ImmunoResearch) in blocking solution for 2 hours at $22^{\circ} \mathrm{C}$. Sections were mounted with Immu-Mount and coverslipped.

At Duke University, images were acquired using a Nikon Eclipse 90i upright microscope equipped with a 100× oil-immersion objective (1.40 NA, Plan Apo VC), A1 confocal scanner controlled by NIS-Elements AR software (Nikon). At the University of Michigan, images were acquired using a Zeiss Observer 7 inverted microscope equipped with a $63 \times$ oil-immersion objective (1.40 NA), LSM 800 confocal scanhead controlled by Zen 5.0 software (Zeiss). Manipulation of images was limited to adjusting the brightness level, image size, rotation and cropping using FIJI (ImageJ) and Illustrator (Adobe).

\section{Protein Deglycosylation Assay}

Eyecups from C57BL/6J mice were collected at P21 and homogenized by pestle, followed by sonication in $250 \mathrm{ml}$ of $1 \%$ sodium dodecyl sulfate and $1 \times$ cOmplete protease inhibitor mixture (Roche, Indianapolis, IN) in PBS. Lysates were cleared at $15,000 \mathrm{rpm}$ for $10 \mathrm{~min}$ at $22^{\circ} \mathrm{C}$. Total protein concentration was measured using the DC Protein Assay kit (Bio-Rad) and $20 \mu \mathrm{g}$ of protein was used for each condition. For PNGase treatment, lysate is combined with $2 \mu \mathrm{L}$ each of Glycoprotein Denaturing Buffer, GlycoBuffer 2 and 10\% NP-40, $1 \mu \mathrm{L}$ PNGase F (NEB, $\mathrm{P} 0708 \mathrm{~L}$ ) and $\mathrm{H}_{2} \mathrm{O}$ as necessary to a final volume of $20 \mu \mathrm{L}$. The reaction is then incubated for $1 \mathrm{hr}$ at $37^{\circ} \mathrm{C}$. For Endo $\mathrm{H}$ (NEB, P0702L) treatment, the same procedure was followed, except that GlycoBuffer 3 was used instead of GlycoBuffer 2. For control experiments, reactions used GlycoBuffer 2 without enzymes. The resulting reactions were terminated by cooling in ice or freezing at $-20^{\circ} \mathrm{C}$. $5 \times$ sample buffer with $100 \mathrm{mM}$ dithiothreitol (DTT) was added to each sample and $5 \mu \mathrm{g}$ total protein loaded on SDS-PAGE for Western blot.

\section{Experimental design and statistical analyses}

All in vivo electroporated mouse retinas were analyzed at postnatal day 21 . All transgenic Xenopus tadpoles were collected at 14 days post injection (stage 43-45). A minimum of three expressing eyes were analyzed for every DNA construct. Animals of both sexes were used for all experimental models. 


\section{Results}

\section{Domain structure of the rod CNG channel subunits}

The domain composition of CNG subunits is shown in Figure 1. Both subunits contain a cytosolic N-terminus, a hexahelical transmembrane core and a cytosolic C-terminus bearing the cGMP-binding domain (Molday and Molday, 1998). The channel's subunits interact through sites located at the C-terminus of CNGa1 and N-terminus of CNGß1 (Trudeau and Zagotta, 2002). The N-terminus of CNG $\beta 1$ is also responsible for binding calmodulin (Grunwald et al., 1998; Weitz et al., 1998) and peripherin-2 (Ritter et al., 2011; Milstein et al., 2017). The latter is conveyed through a relatively large GARP domain (Sugimoto et al., 1991; Colville and Molday, 1996), which can be sub-divided to a region containing four short proline-enriched repeats responsible for peripherin-2 binding (Ritter et al., 2011; Milstein et al., 2017) and a region of high glutamic acid content. Notably, rods also express two soluble proteins, GARP1 and GARP2, formed through alternative splicing of the Cngb1 gene and include various fragments of the CNGß1 N-terminus (Ardell et al., 1995; Ardell et al., 1996; Ardell et al., 2000).

\section{The CNG channel utilizes a conventional trafficking pathway to reach the outer segment}

Membrane proteins can utilize two secretory pathways to reach their final destinations: the conventional pathway through both the ER and Golgi and the unconventional pathway directly from the ER. One way to determine which pathway is used by a particular protein is to assess whether its glycosylation is sensitive to Endoglycosidase $\mathrm{H}$ (Endo $\mathrm{H}$ ). N-glycosylation takes place in ER, where high-mannose oligosaccharides are transferred to proteins. This highmannose $\mathrm{N}$-glycan is sensitive to Endo $\mathrm{H}$ cleavage, so proteins exiting from the ER can be fully deglycosylated by this enzyme. If a glycoprotein is transferred and is processed through the Golgi, its oligosaccharide moieties are modified to produce hybrid oligosaccharide chains that are resistant to Endo $\mathrm{H}$ cleavage. Accordingly, proteins trafficked through the unconventional secretory pathway are Endo $\mathrm{H}$-sensitive and those using the conventional pathway are Endo $\mathrm{H}$ resistant. In contrast, all $\mathrm{N}$-linked glycoproteins are sensitive to general amidases, like PNGase $\mathrm{F}$.

To understand how outer segment trafficking utilizes these two secretory pathways, we treated mouse retinal lysates with PNGase $\mathrm{F}$ and Endo $\mathrm{H}$ to examine the glycosylation status of eight outer segment-resident membrane proteins (Figure 2). We found that the electrophoretic mobility of three proteins, CNG $\beta 1$, guanylyl cyclase-2 (GC-2) and Rom-1, did not change upon PNGase $\mathrm{F}$ or Endo $\mathrm{H}$ treatment (Figure $2 \mathrm{~A}$ ), suggesting that they are not $\mathrm{N}$-linked glycoproteins. 
The other five proteins, CNGa1, rhodopsin, peripherin-2, guanylyl cyclase-1 (GC-1) and ABCA4, had increased mobility upon PNGase F treatment demonstrating that they are N-linked glycoproteins. We also treated retinal lysates with Endo $\mathrm{H}$ and found that three proteins, CNGa1, GC-1 and rhodopsin, are resistant to this treatment (Figure 2B), indicating that they are trafficked via the conventional pathway. Whereas this route of outer segment delivery was previously established for rhodopsin (Deretic and Papermaster, 1991), the findings for CNGa1 and GC-1 represent original observations. Notably, the behavior of GC-1 is consistent with our previous result that it is delivered to the outer segment in a complex with rhodopsin (Pearring et al., 2015). Consistent with previous observations (Connell and Molday, 1990; Illing et al., 1997), ABCA4 was completely deglycosylated by Endo $\mathrm{H}$, whereas peripherin-2 displayed a mixed pattern whereby the majority was deglycosylated and a smaller fraction, shown to be associated with Rom-1 (Conley et al., 2019), was not (Figure 2C).

These results reveal a peculiar analogy between the trafficking of the peripherin-2/Rom1 and CNGa1/CNG 1 complexes. Both complexes utilize the conventional secretory pathway for outer segment delivery and only one subunit in the complex becomes $\mathrm{N}$-link glycosylated en route.

\section{Outer segment localization of the CNG channel requires subunit pre-assembly and is driven by the CNG $\beta 1$-subunit}

To investigate the relationship between the CNG channel subunits delivery to the rod outer segment, we first expressed epitope-tagged constructs representing each subunit in both WT and CNG $\beta 1$ knockout (Cngb1-X1//) mice. The Cngb1-X1/- mouse has a targeted deletion of exons 1 and 2 from the Cngb1 gene resulting in the CNGß1 knockout (Zhang et al., 2009). It is also characterized by an $\sim 30$-fold reduction in the expression level of CNGa1, suggesting that the cellular stability of CNGa1 relies on its association with CNG $\beta 1$. Expression of CNGa1-MYC in WT mice resulted in its predominantly normal outer segment localization (Figure 3A). However, when expressed in Cngb1-X1/- mice, CNGa1-MYC was localized in both outer segments and other cellular compartments in a pattern typical for untargeted membrane proteins expressed in mouse rods (Pearring et al., 2014). These observations suggest that CNG $\beta 1$ contains targeting information required for the outer segment delivery of the entire channel. Consistently, co-expression of CNGa1-MYC with CNGB1-FLAG in Cngb1-X1/- rods redirected CNGa1-MYC to the outer segment, along with expressed CNG $\beta 1$ (Figure 3B).

There is another important aspect of the data shown in Figure 3A. The fact that all overexpressed CNGa1 is normally targeted in WT rods implies that these cells naturally express 
more CNG $\beta 1$ than is incorporated in the mature channel. This extra CNG $\beta 1$ is normally cleared by the cell but can become a part of a mature channel when CNGa1 is overexpressed. Further evidence that the cellular level of the mature CNG channel is determined by the amount of expressed CNG $\beta 1$ comes from the behavior of CNG 1 1-FLAG expressed in WT and $C n g b 1-X 1^{-/-}$ rods. Whereas CNG 1 1-FLAG was normally localized to outer segments of $C n g b 1-X 1^{-/-}$rods, a large fraction was retained in the soma of WT rods in a pattern suggesting retention in the biosynthetic membranes (Figure $3 \mathrm{C}$ ). This suggests that knockout rods contain enough CNGa1 to associate with expressed CNG $\beta 1-F L A G$ and form a mature channel, but WT rods do not express enough CNGa1 to assemble with both endogenous CNG $\beta 1$ and overexpressed CNG $\beta 1$-FLAG. Consistent with this interpretation, co-expression of CNGa1-MYC with CNG $\beta 1$ FLAG in WT rods resulted in normal localization of both subunits in the outer segment (Figure 3D), showing that increased CNGa1 levels are sufficient to assemble with both endogenous and overexpressed CNG $\beta 1$.

\section{CNG $\beta 1$ 's C-terminal "RVXP” motif is not required for outer segment localization}

Previous studies of the olfactory CNG channel localization in cell culture showed that its ciliary targeting requires a "RVXP" motif on the C-terminus of the CNG $\beta 1 \mathrm{~b}$ subunit, which is spliced from the same Cngb1 gene as CNGß1 expressed in rods (Jenkins et al., 2006; Jenkins et al., 2009). Therefore, we examined whether this sequence in CNG $\beta 1$ (RVSP in the mouse) is required for the outer segment CNG channel targeting in rods. We generated a mutant construct in which these four residues were replaced with alanines (CNG $\left.\beta 1_{4 \mathrm{~A}}\right)$ and expressed it in Cngb1$X 1^{-/}$rods. The outer segment localization of this mutant was indistinguishable from the WT CNG $\beta 1$ control (Figure 4A), demonstrating that the "RVXP" motif does not confer outer segment targeting. A similar result was obtained upon transgenic expression of the corresponding mutant of human CNGß1 subunit in Xenopus rods. Both outer segment targeting and subcellular localization of the mutant construct to the outer segment plasma membrane were normal (Figure 4B). Notably and unlike in WT mice, we did not observe CNG $\beta 1$ retention in the biosynthetic membranes upon overexpression, which may be explained by differences in relative overexpression levels and/or cross-species differences in the clearance efficiency of unprocessed proteins.

\section{Outer segment targeting of CNG $\beta 1$ is mediated by its $\mathbf{N}$-terminus}

In the next set of experiments, we undertook a search for the outer segment targeting and sorting signal(s) within CNG $\beta 1$. We first expressed the cytosolic C-terminus of human CNG $\beta 1$ in transgenic Xenopus (CT construct in Figure 1). To ensure membrane-association while 
preserving its relative membrane topology, this construct was fused with an $\mathrm{N}$-terminal singlepass transmembrane domain, subcloned from the activin receptor. However, the resulting TMCNG $\beta 1_{\text {cT }}$ construct was retained in the biosynthetic membranes (Figure $5 \mathrm{~A}$ ) precluding us from analyzing its targeting capacity. To circumvent this problem, we appended the CT sequence to a construct containing YFP and the untargeted lipidation sequence of rhodopsin (YFP-Rhoct $\Delta 5$ ), a strategy previously applied to achieve membrane attachment of C-terminal protein fragments (Tam et al., 2004; Salinas et al., 2013) (YFP-RhoCT $\Delta 5-C N G \beta 1_{\mathrm{cT}}$; Figure 5B). However, expression of the YFP-RhoCT $\triangle 5-C N G \beta 1_{\text {CT }}$ construct resulted in a pattern indicative of a soluble protein, suggesting that the long full-length CT construct prevented posttranslational lipidation of the rhodopsin C-terminus. Therefore, we resorted to testing a short C-terminal sequence of 28 amino acids previously suggested to contain outer segment targeting information (Kizhatil et al., 2009). Somewhat unexpectedly, when we expressed the YFP-Rhoct $\triangle 5-C N G \beta 1_{\text {cT28 }}$ its subcellular distribution was essentially identical to that of the base YFP-Rho ${ }_{\mathrm{CT} \Delta 5}$ construct (Figures 5C,D). Both constructs followed a "default" distribution pattern for untargeted membrane-associated proteins, in which the majority is localized in the outer segment but appreciable fractions are also present in the plasma membrane of the cell body and the synaptic region (Baker et al., 2008).

Next, we focused on the targeting properties of the cytosolic CNG $\beta 1 \mathrm{~N}$-terminus (NT construct in Figure 1). Its proper membrane attachment and topology were established by fusing with the single-pass transmembrane domain from R9AP lacking specific targeting information (Baker et al., 2008; Pearring et al., 2014). The resulting CNG $\beta 1_{\mathrm{NT}}-\mathrm{TM}$ construct was localized exclusively to the outer segment, suggesting that it bears sufficient targeting information (Figure $5 \mathrm{E})$. However, when we expressed the same construct as a soluble protein (CNG $\left.\beta 1_{\mathrm{NT}}\right)$, it was also localized to the outer segments with the same staining pattern (Figure 5F). The latter is inconsistent with the well-described distribution of soluble proteins, such as GFP, located predominantly in the cytosol-rich inner segment ((Tam et al., 2000; Najafi et al., 2012); Figure $5 \mathrm{G})$. The distribution of $C N G \beta 1_{N T}$ resembles of soluble GARP1/2 proteins comprised predominantly from the parts of the CNGß1 N-terminus (Hüttl et al., 2005; DeRamus et al., 2017) and suggests that its outer segment localization is conveyed through an interaction with another outer segment-resident protein, such as peripherin-2 located at the disc rims or CNGa1 located in the outer segment plasma membrane (Poetsch et al., 2001; Ritter et al., 2011). We then expressed a soluble construct encoding CNG $\beta 1$ 's GARP domain (CNG $\beta 1_{\text {GARP; }}$ Figure $5 \mathrm{H}$ ) and found that it is distributed like the entire $\mathrm{N}$-terminus. Because the interaction site with CNGa1 resides outside the GARP domain (Figure 1), this result favors peripherin-2 as the 
interacting partner for these constructs. This was further supported by the analysis of tangential sections cut across rod outer segments expressing soluble $\mathrm{N}$-terminal constructs (Figure 6). Both $C N G \beta 1_{\mathrm{NT}}$ and $\mathrm{CNG} \beta 1_{\mathrm{GARP}}$ displayed a flower petal-like pattern, which corresponds to invaginating incisures at the disc rims. This pattern is similar to that of peripherin-2 but is different from that of CNG $\beta 1$, which lacks immunostaining of the disc incisures (Figure 6).

\section{CNG $\beta 1$ 's GARP domain encodes both outer segment targeting and peripherin-2 interaction site}

Demonstrating that the GARP domain of CNG $\beta 1$ binds to the disc rims might suggest that the CNG channel uses an interaction with peripherin-2 for outer segment delivery rather than utilizing its own targeting signal. To explore this possibility, we expressed smaller fragments of the CNG $\beta 1$ N-terminus - CNG $\beta 1_{\text {Cam }}, C N G \beta 1_{R}$ and $C N G \beta 1_{G l u}$ (Figure 1) - as both soluble and membrane-anchored proteins. Soluble CNG $\beta 1_{\text {cam }}$ was localized predominantly in the inner segment, suggesting that it is not engaged in any outer segment interactions, whereas the corresponding membrane-anchored construct (CNGß1 $\left.\mathrm{CaM}^{-T M}\right)$ was retained in the biosynthetic membranes (Figure $7 \mathrm{~A}$ ). Soluble $\mathrm{CNG} \beta 1_{\mathrm{R}}$ was biased to the outer segment where it tended to accumulate at the periphery (Figure 7B). However, a portion of this construct was also found in the cell body and synaptic termini, suggesting that its affinity for periphern- 2 is not as high as that of longer N-terminal constructs (Figure $5 E, G$ ). Membrane-anchored CNG $\beta 1_{R}-T M$ was successfully exiting the biosynthetic membranes and delivered to both inner and outer segments (Figure 7B), indicating that it lacks specific outer segment targeting information. Within the outer segment, $C N G \beta 1_{R}-T M$ was located at disc incisures similar to longer $\mathrm{N}$-terminal constructs, as evidenced from the flower petal-like pattern seen in tangential sections (Figure $7 \mathrm{~B})$. Together, these data suggest that the $C N G \beta 1_{R}$ region is sufficient for peripherin-2 interaction, but not for specific outer segment targeting.

We next analyzed CNG $\beta 1_{\text {Glu }}$ constructs (Figure $7 \mathrm{C}$ ). Soluble CNG $\beta 1_{\text {Glu }}$ behaved as a typical cytosolic protein with diffuse staining within the photoreceptor cytoplasm, suggesting the lack of specific outer segment interactions. The membrane-anchored CNG $\beta 1_{\text {Glu }}$-TM was found in both inner and outer segments. However, its inner segment fraction was located inside the cell and not within the surrounding plasma membrane. This suggests that only a portion of this construct is properly processed by the biosynthetic membranes, precluding us from determining whether $\mathrm{CNG} \beta 1_{\text {Glu }}$ may contain an outer segment targeting signal. To avoid protein misprocessing, we expressed $\mathrm{CNG} \beta 1_{\text {Glu }}$ as a lipidated construct by adding a C-terminal CCIIL sequence for double lipidation (palmitoylation and geranylgeranylation) previously introduced in 
similar studies (Tam et al., 2004; Baker et al., 2008; Pearring et al., 2014) (Figure 7D). We have found that $\mathrm{CNG} \beta 1_{\mathrm{Glu}} \mathrm{CCIIL}$ was localized exclusively in the outer segments, whereas the control untargeted GFP-CCIIL construct displayed a typical default pattern with an appreciable amount localized in other parts of the rod cell. This result shows that CNG $\beta 1_{\text {Glu }}$ contains a specific outer segment targeting signal. Within the outer segment, CNG $\beta 1_{\mathrm{Glu}}-\mathrm{CCIIL}$ was evenly distributed across all membranes without showing any bias toward periphery. Combined with the behavior of the soluble $\mathrm{CNG} \beta 1_{\mathrm{Glu}}$ construct, this suggests that this region of CNG $\beta 1$ is not sufficient for binding to peripherin-2.

\section{Discussion}

Protein targeting to the light-sensitive photoreceptor outer segment is still far from being understood and remains a subject of active investigation. Except for a few proteins shown to be delivered within larger complexes, such as GC-1 and PRCD associated with rhodopsin (Pearring et al., 2015; Spencer et al., 2016) or RGS9 and Gß5 associated with R9AP (Hu and Wensel, 2002; Keresztes et al., 2004; Krispel et al., 2006; Gospe et al., 2011), most membrane proteins have targeting information encoded in their sequences. Amongst them, the CNG channel is particularly interesting because it needs to be both delivered to the outer segment and then sequestered to the plasma membrane surrounding the discs. In this study, we demonstrated that the rod outer segment delivery of this channel requires pre-assembly of its constituent subunits upon their biosynthesis and that the targeting signal is encoded within the glutamic acid-rich region of CNG $\beta 1$ 's GARP domain. Whereas acidic clusters have previously been associated with packaging membrane proteins into clathrin-coated vesicles (Navarro Negredo et al., 2017), to our knowledge, this is the first time an acidic cluster has been implicated in ciliary targeting of a membrane protein. This targeting signal is sufficient for outer segment localization but not subsequent outer segment plasma membrane sequestration, suggesting that the final sorting of the CNG channel to the outer segment plasma membrane occurs independently of its initial targeting.

We further showed that the cellular level of the mature CNG channel in rods is determined by the expression level of CNG $\beta 1$. This follows the pattern in which the total amount of a mature multi-subunit protein complex is determined by the expression level of one of its subunits. The best studied example in photoreceptors is the RGS9-Gß5-R9AP GTPase activating complex for transducin, whose cellular content is set by the expression of R9AP, while the fractions of other subunits expressed in excess of R9AP are efficiently cleared by the cell (Keresztes et al., 2004; Krispel et al., 2006). 
Another aspect of outer segment trafficking explored in this study is that some proteins, such as rhodopsin, use the conventional secretory pathway through the ER and Golgi (Deretic and Papermaster, 1991; Deretic et al., 1998; Murray et al., 2009), while others, such as ABCA4, use the unconventional pathway bypassing the Golgi (Illing et al., 1997; Tsybovsky et al., 2011). Peripherin-2, known to interact with the CNG channel in outer segments, is also delivered through the unconventional pathway (Connell and Molday, 1990). The exception is a fraction of peripherin-2 engaged in the hetero-tetrameric complex with Rom-1, which is diverted into the conventional pathway (Zulliger et al., 2015; Conley et al., 2019). The latter is species-specific: it was documented for mice, yet the entire pool of peripherin-2 in bovine and Xenopus is delivered via the unconventional pathway (Connell and Molday, 1990; Tian et al., 2014).

Our new data show that the CNG channel is delivered to the outer segment via the conventional pathway, which may suggest that the CNG channel and peripherin-2 are trafficked to this compartment independently of one another, particularly because the entire pool of peripherin-2 was shown to utilize the unconventional pathway in Xenopus (Tian et al., 2014). However, another Xenopus study employing fluorescence complementation assays concluded that the interaction between the CNG channel and peripherin-2 first takes place in the inner segment (Ritter et al., 2011). Furthermore, CNG $\beta 1$ is completely absent from the outer segment membrane material of peripherin-2 knockout mice despite all other known outer segment proteins, including CNGa1 and Rom-1, being found in this preparation (Spencer et al., 2019). This argues that the CNG $\beta 1$ cannot be delivered to the outer segment without peripherin-2 and they ought to interact before reaching this destination. A possible trafficking mechanism reconciling all of these observations was proposed in a recent study suggesting that, at least in cones, peripherin- 2 is trafficked through the late endosome before entering the outer segment (Otsu et al., 2019). Likewise, the CNG channel might pass through endosomes, based on its mislocalization from the outer segment in conditional double knockout mice lacking the endocytic adaptor proteins Numb and Numb-like in rods (Ramamurthy et al., 2014). The authors further showed that, in cell culture, Numb binds and re-directs CNGa1 to endosomes. Therefore, it is conceivable that the CNG channel and peripherin-2 are first trafficked to the inner segment endosomes using the conventional and unconventional secretory pathways, respectively, and then are delivered to the outer segment as a complex.

If the CNG channel and peripherin-2 are in fact delivered to the outer segment as a complex, then how do they next segregate into two different membrane sub-compartments - the discs and the plasma membrane? It logical to assume that they segregate upon the remodeling 
of outer segment membranes during the process of disc enclosure (Spencer et al., 2020a), after which they remain connected in-trans forming a link between the disc rim and the plasma membrane. However, no direct evidence for this mechanism have been obtained so far. It also remains unknown whether any additional proteins, such as the $\mathrm{Na} / \mathrm{Ca}-\mathrm{K}$ exchanger associated with the CNG channel, are involved in the channel's plasma membrane segregation. It has been proposed that this process involves a cytoskeletal protein, ankyrin-G (Kizhatil et al., 2009). However, subsequent proteomic studies have not identified any ankyrin-G peptides in the outer segment (Skiba et al., 2013; Spencer et al., 2019) challenging the existence of ankyrin-G in this subcellular compartment. Thus, elucidating the exact outer segment trafficking route of the CNG channel and the mechanism responsible for its subsequent sorting into the outer segment plasma membrane remain the challenges for future studies. 


\section{Figures}
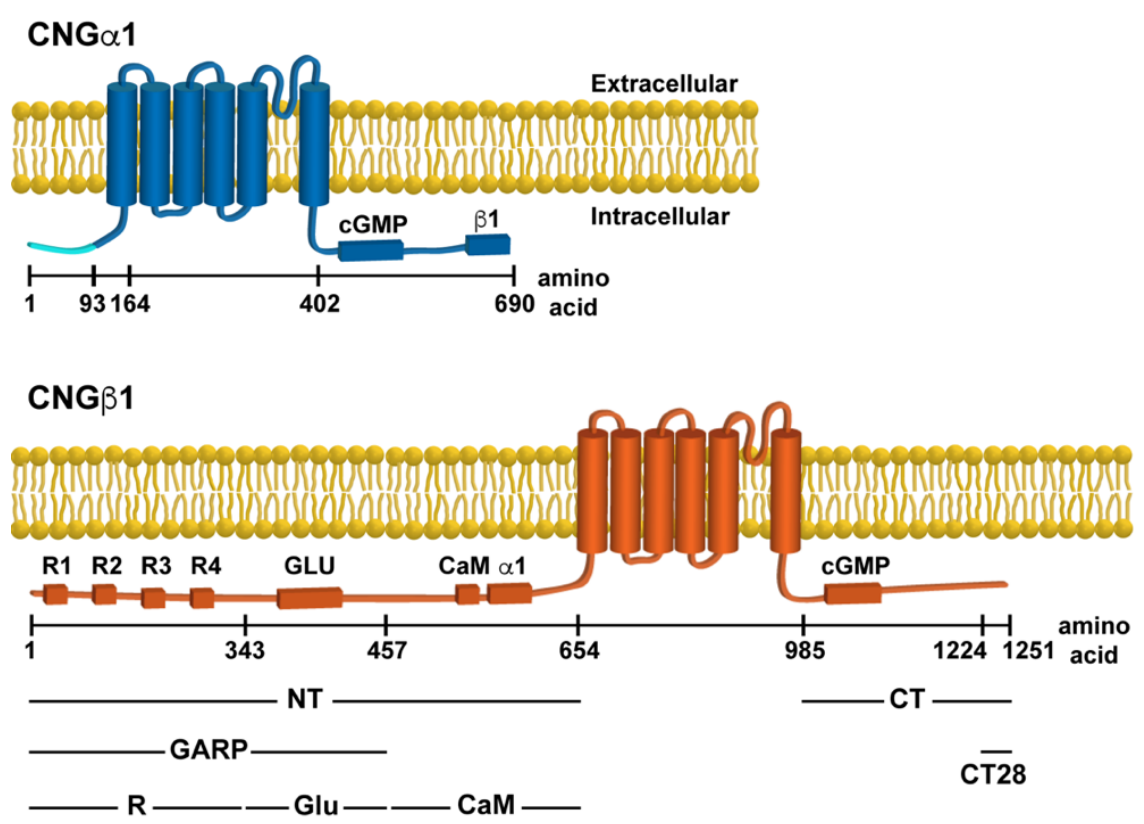

Figure 1. Domain composition of CNGa1 and CNGß1. Cytosolic domains include: cGMP binding; calmodulin (CaM) binding; CNGa1 ( $\alpha 1)$ and CNG $\beta 1$ ( $\beta 1)$ binding; glutamic-acid rich region (GLU) and four proline-rich repeats (R1-R4). The boundaries of CNG $\beta 1$-derived constructs expressed in this study shown below the cartoon. The numbering of amino acids corresponds to human protein sequences. Notably, the first 92 amino acids of CNGa1 (marked in light blue) are cleaved during intracellular CNG channel processing (Molday et al., 1991). 


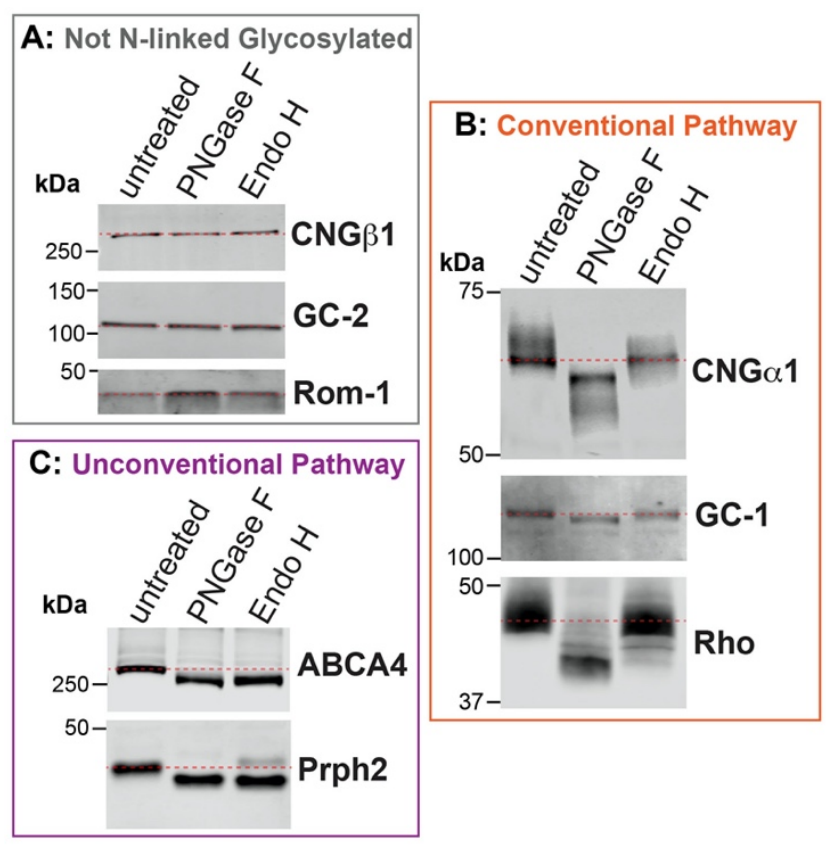

Figure 2. The rod CNG channel is trafficked using the conventional secretory pathway. Mouse retinal lysates (untreated) were incubated with PNGase F or Endo $\mathrm{H}$ and analyzed by Western blotting. (A) Electrophoretic mobility of non-glycosylated proteins CNG $\beta 1$, guanylate cyclase-2 (GC-2) and Rom-1, is unaffected by enzymatic treatments. (B) CNGa1, guanylate cyclase-1 (GC-1) and rhodopsin (Rho) are sensitive to PNGase F and resistant to Endo H treatment, indicating their processing through the conventional secretory pathway. (C) ABCA4 and peripherin-2 (Prph2) are sensitive to both PNGase F and Endo $\mathrm{H}$ treatments, indicating their processing through the unconventional secretory pathway. Dashed red lines are used to mark the positions of untreated protein bands. $10 \mu \mathrm{g}$ of total protein was loaded in each lane. 


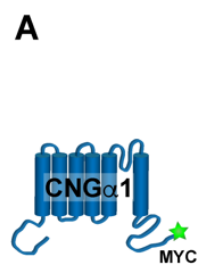

C

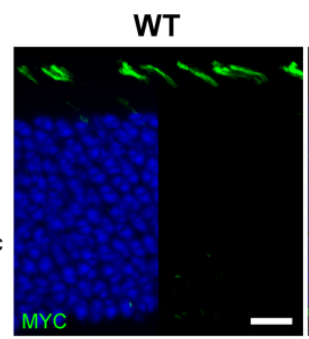

WT

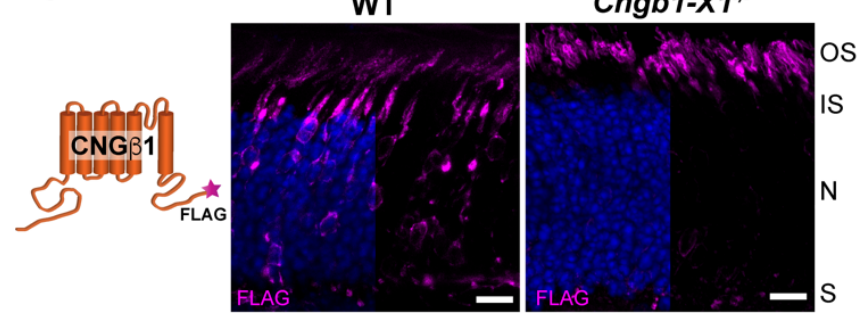

B

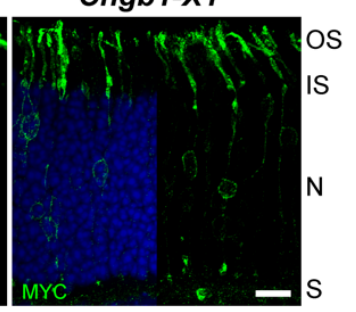

Cngb1-X1\%

D
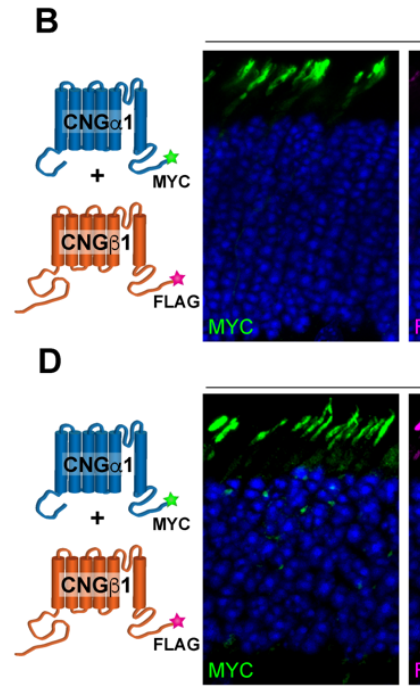

Cngb1-X1/

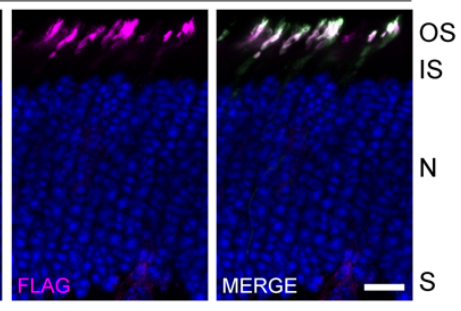

WT

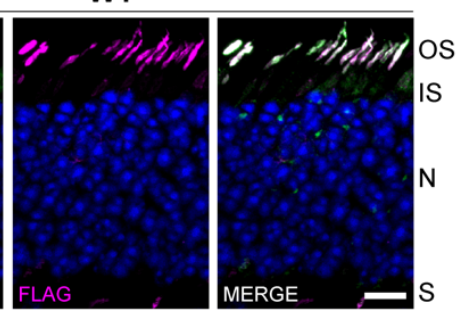

Figure 3. Outer segment localization of the CNG channel requires expression of the

CNG $\beta 1$ subunit. (A) Retinal cross-sections from wild-type (WT) and Cngb1-X1/- rods transfected with MYC-tagged, full-length mouse CNGa1. (B) Cngb1-X1/- rods were cotransfected with CNGa1-MYC and CNGß1-FLAG. The merged image is shown in the right panel. (C) WT or Cngb1-X1/- rods transfected with FLAG-tagged, full-length mouse CNG $\beta 1$. (D) WT rods were co-transfected with CNGa1-MYC and CNGß1-FLAG. In all panels, retinal sections were stained for each construct using an anti-MYC (green) and/or anti-FLAG (magenta) antibodies as indicated in the panel and nuclei are stained by Hoechst (blue). Cartoon of transfected constructs are depicted on the left. Scale bar, $10 \mu \mathrm{m}$. Here and in the following figures, photoreceptor cell layer abbreviations: outer segment (OS), inner segment (IS), nucleus (N), and synapse (S). 

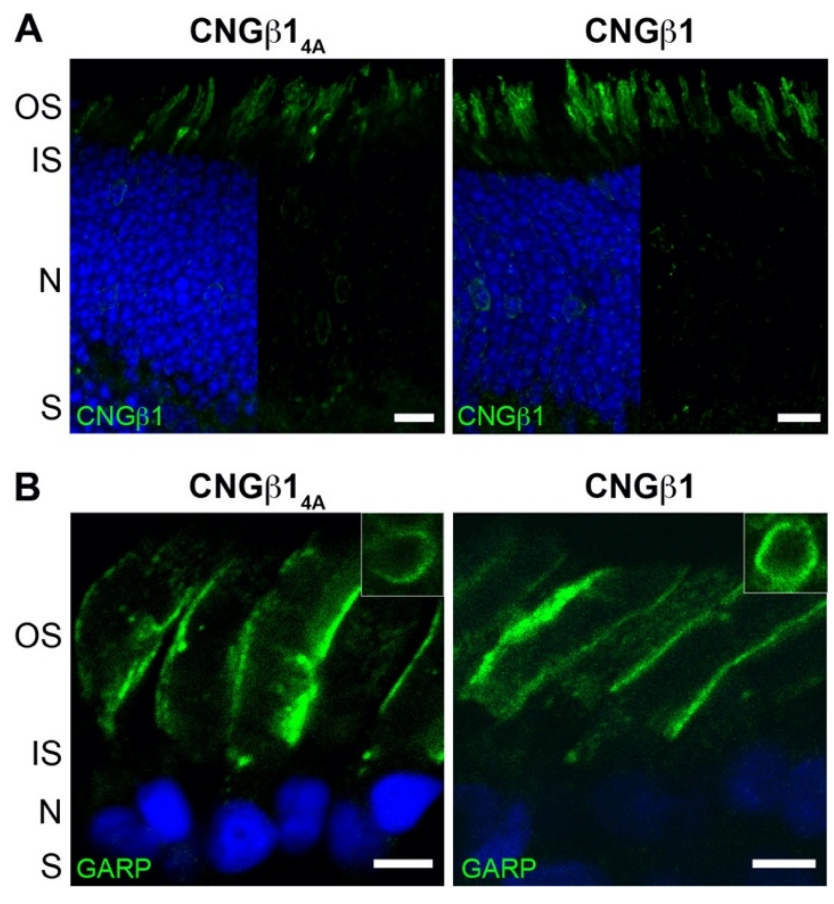

Figure 4. The C-terminus "RVSP" motif is not involved in CNG channel localization to the plasma membrane of the outer segment. (A) Cngb1-X1\% rods were transfected with untagged mouse $C N G \beta 1_{4 \mathrm{~A}}$ mutant or $\mathrm{CNG} \beta 1$ control constructs. Retinal cross-sections were stained for each construct using an anti-CNG $\beta 1$ (green) antibody. Scale bar, $10 \mu \mathrm{m}$. (B) Transgenic Xenopus rods expressing full-length human CNG $\beta 1_{4 \mathrm{~A}}$ mutant or CNG $\beta 1$ control. Retinal cross-sections were stained for each construct using an anti-GARP (green) antibody. Scale bar, $5 \mu \mathrm{m}$. Nuclei are counterstained with Hoechst (blue). 

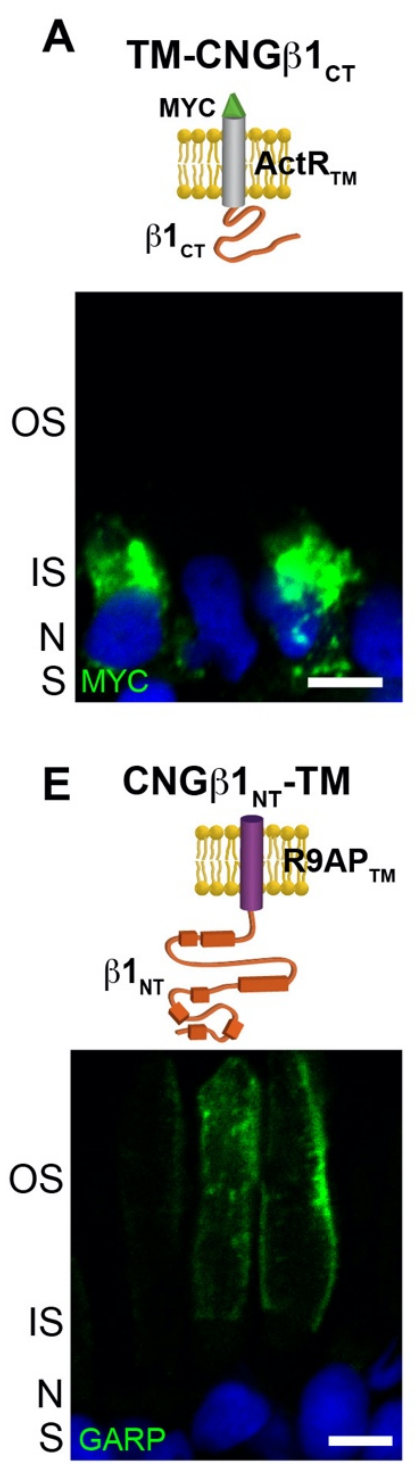

B YFP-Rho ${ }_{\mathrm{CT} \triangle 5}{ }^{-}$

CNG $\beta 1_{\text {CT }}$
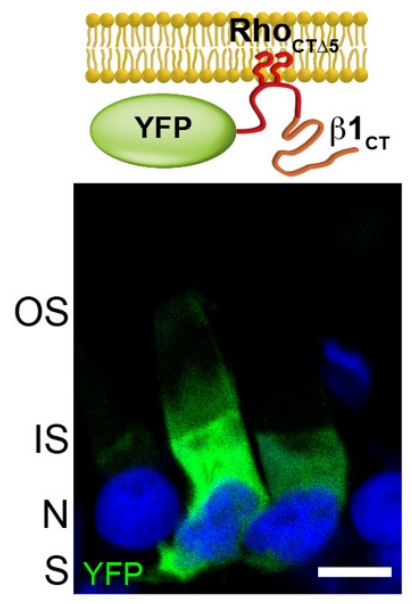

F $\quad$ CNG $\beta 1_{\mathrm{NT}}$
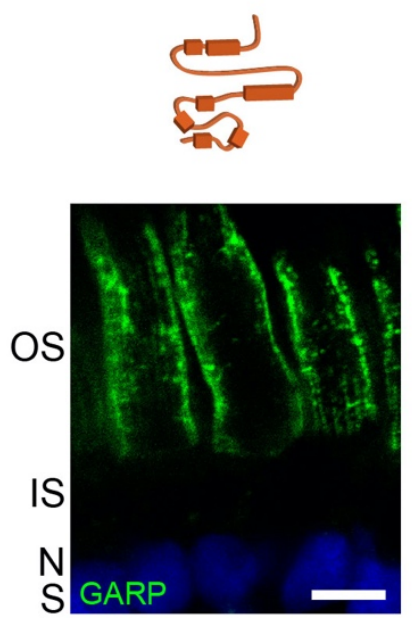
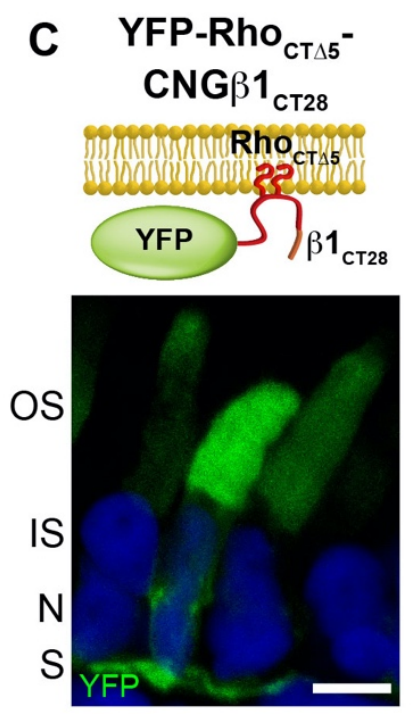

G

GFP

\section{GFP}

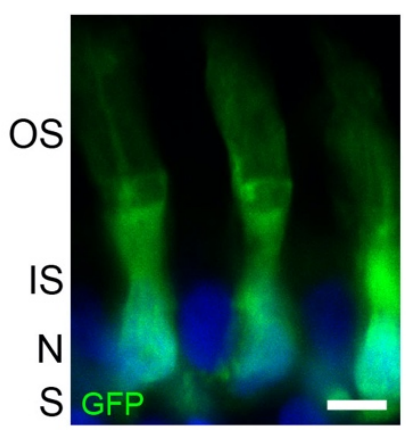

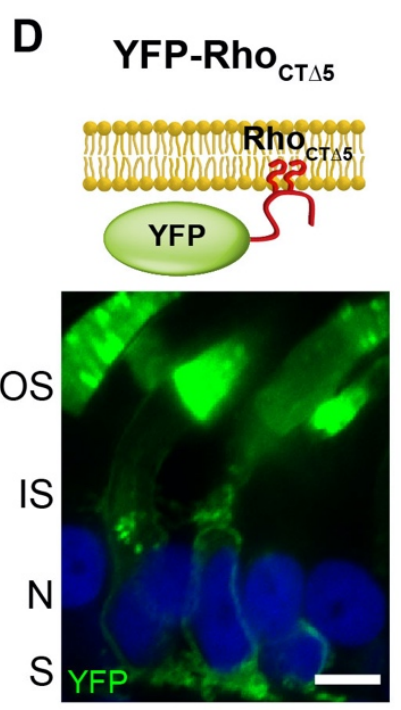

H CNG $\beta 1_{\text {GARP }}$

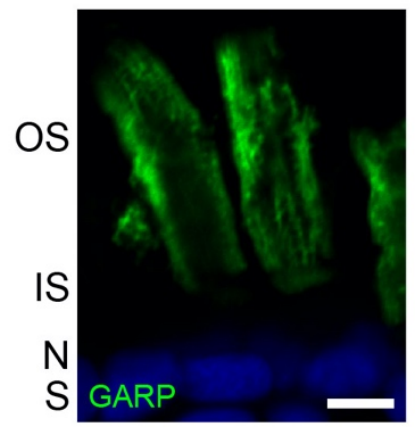

Figure 5. CNG $\beta 1 \mathrm{~N}$-terminal GARP domain is confined to the rod outer segment. Retinal cross-sections from transgenic Xenopus rods expressing (A) membrane-anchored TMCNG $\beta 1_{\text {cт, }}$, (B) lipidated YFP-Rhoct $\triangle 5-C N G \beta 1_{\text {cT }}$, (C) lipidated YFP-RhocT $\triangle 5-C N G \beta 1_{\text {cт28, (D) }}$

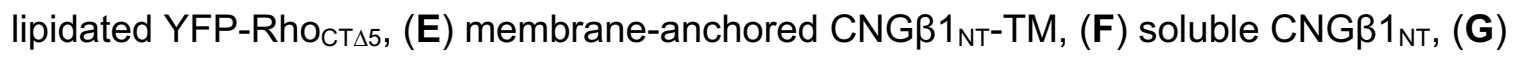
soluble GFP and $(\mathbf{H})$ soluble CNG $\beta 1_{\text {GARP }}$ constructs. Cartoon of transfected constructs are shown above their corresponding panel. Constructs that include N-terminal of human CNG $\beta 1$ were detected using an anti-GARP antibody. Nuclei are counterstained with Hoechst (blue) and scale bar is $5 \mu \mathrm{m}$ in all panels. 

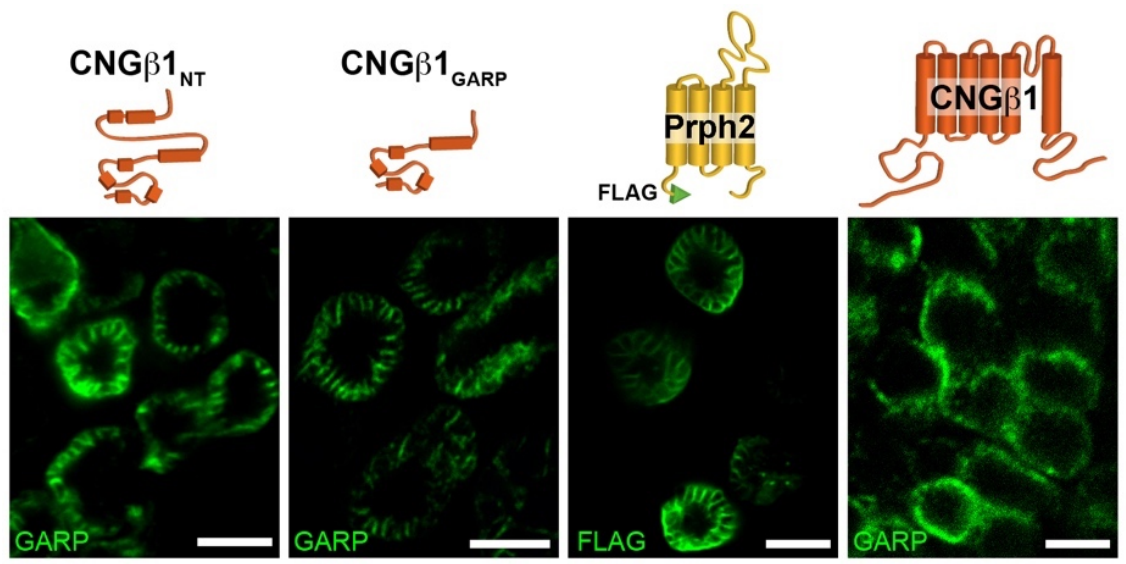

Figure 6. CNG $\beta 1$ 's N-terminal GARP domain localizes to disc incisures within rod outer

segments. Tangential sections through Xenopus rod outer segments expressing soluble CNG $\beta 1_{\mathrm{NT}}$ and $\mathrm{CNG} \beta 1_{\mathrm{GARP}} ; \mathrm{FLAG}$-tagged full-length bovine peripherin-2 or untagged full length CNG $\beta 1$. Cartoon of transfected constructs are shown above their corresponding panel. Constructs that include $\mathrm{N}$-terminal of human CNG $\beta 1$ were detected using an anti-GARP antibody. Scale bar, $5 \mu \mathrm{m}$ in all panels. 

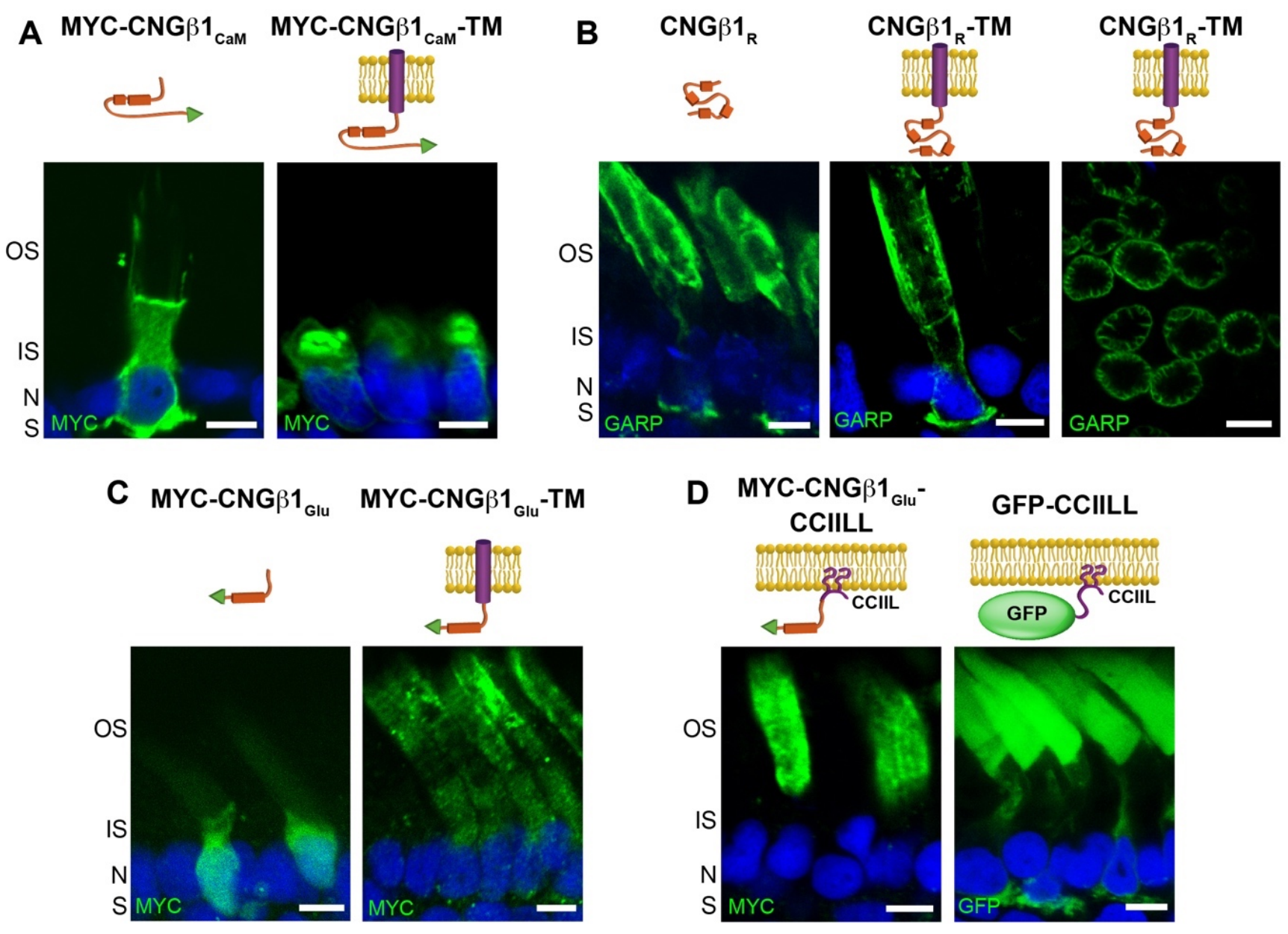

Figure 7. CNG $\beta 1$ 's GARP domain contains separate sites for peripherin-2 binding and outer segment targeting. Retinal cross-sections from transgenic Xenopus rods comparing localization of (A) soluble and membrane-anchored CNG $\beta 1_{\mathrm{CaM}}$; (B) soluble and membraneanchored $C N G \beta 1_{R}$ and a tangential image of outer segment's expressing $C N G \beta 1_{R}-T M ;(C)$ soluble and membrane-anchored CNG $\beta 1_{\text {Glu }}$; and (D) CNG $\beta 1_{\text {Glu }}$ or GFP fused to a C-terminal CCIIL double lipidation anchor (D). Cartoon of transgenic constructs are shown above their corresponding panel. Constructs that include the N-terminal of human CNG $\beta 1$ were detected using an anti-GARP antibody. All other constructs were N-terminally tagged with the MYC epitope and detected using an anti-MYC antibody. Scale bar, $5 \mu \mathrm{m}$. Nuclei are counterstained with Hoechst (blue). 
Table 1:

\begin{tabular}{|c|c|}
\hline Primer Name & Sequence (5' -> 3') \\
\hline Mcngb1 fwd & ATGTTGGGCTGGGTCCAAAGGG \\
\hline mCNGb1_rev & TCACTCCGCCCCСTCTTTCTTC \\
\hline mCNGB1 ssF1 & GCACAGATCCCAGAACCTTG \\
\hline mCNGB1 ssF2 & GAGCAGGAAGAGGATGAGGA \\
\hline mCNGB1 ssF3 & TGCAGCAGGAAGAAGCTACC \\
\hline mCNGB1 ssF4 & GCGGGGACATCATTACAGAC \\
\hline mCNGB1 ssF5 & GCAGAACCGTGTCAAGACCT \\
\hline mCNGB1 ssF6 & CCGAAGCTCTTCAATGCTG \\
\hline mCNGB1 ss7 & GCATCTTGTCCGGAAGTTGT \\
\hline mCNGB1 ss8 & GAGGGTTGATGCCAAGTTTG \\
\hline mCNGB1 ss9 & GGGACTCAGCTGGTGACAG \\
\hline mCNGB1 ss 10 & CACCAAACAGCTATCCAGCA \\
\hline mCNGB1 ss11 & ATTCTGCTCAAGCCACCTGA \\
\hline Agel_hCNGB_F1 & CACATAACCGGTATGTTGGGCTGGGTCCAGAGG \\
\hline hCNGB1ssF1 & TCACAGCATCACGGAGGACC \\
\hline hCNGB1ssF2 & GTGCAGACCATCAGCATCCT \\
\hline hCNGB1ssF3 & TCAGGAGTGCCTGCCACGAA \\
\hline hCNGB1ssF4 & GAGGAGCACTATTGCGACAT \\
\hline hCNGB1ssF5 & GTGTACAGGGTCATCAGGAC \\
\hline hCNGB1ssF6 & GTTAGCAAAGTCGCACTCTT \\
\hline hCNGB1ssF7 & GGCAAAAGGCGGCAAACTTG \\
\hline hCNGBtmd-F1 & GGATCCATGCTGACCAACCTGATGTATG \\
\hline hCNGBtmd-R1 & ACCGGTATCACATCTCTCATCTGTCCGA \\
\hline hCNGBntd-F1 & GGATCCATGTTGGGCTGGGTCCAGAG \\
\hline hCNGBntd-R1 & GACCGGTATCAGGTTGGTCAGCGGGTCA \\
\hline hCNGB1-ssR1 & GTGGAGAGCTCGGTGGAGAC \\
\hline hCNGB1-ssR2 & CCAACAGCCAGCAAGCTTAT \\
\hline Agel_EGFP-Fwd & CACATAACCGGTATGGTGAGCAAGGGCGAGGAGCT \\
\hline Age_myc-F & CACATAACCGGTATGGAACAAAAACTCATCTCAGA \\
\hline Notl_myc_Rev & GCATTGGCGGCCGCTCACAGATCCTCTTCTGAGATAAGCTT \\
\hline hCNGBtmd-Notl-R1 & AGAGTCGCGGCCGCTTACACATCTCTCATCTGTCCGA \\
\hline hCNGB-GFP-Rsplice & TCCTCGCCCTTGCTCACCATCACATCTCTCATCTGTCCGA \\
\hline Notl_GARP_Rev & AGAGTCGCGGCCGCTTTATCCTGAACTGGCAGCCTCGG \\
\hline Notl-hCNGBntd-R & AGAGTCGCGGCCGCTTACAGGTTGGTCAGCGGGTCAATG \\
\hline hB1-343-Notl-R & AGAGTCGCGGCCGCTTTACTTCTCCACAGCTTTGTTCTC \\
\hline hB1343-Notl-R New & ATAGAGTCGCGGCCGCTTTACTTCTCCACAGCTTTGTTCTCTTC \\
\hline Agel_mCNGA1_Fwd & CAATGCACCGGTGCCGCCACCATGAAGACAAATATTATCAATA \\
\hline Notl mCNGA1 Rev & GCATTGGCGGCCGCTCAGTCCTGTAGAGACTCCGT \\
\hline mCNGA1-ssF1 & TTCCAGAGGACGGAAACAAG \\
\hline mCNGA1-ssR1 & GGTGGCGAAAATTAAAACTCC \\
\hline xR9APtm_Rev & $\begin{array}{l}\text { TTACAGAATAGAATAGAGTGTAATAGCTACAAGGGCTGTTCCACATAAAAGCAAG } \\
\text { GACACAATTAACTGTCCGTCCAGGTTGGTCAGCGGGTCAATG }\end{array}$ \\
\hline hCNGB-AAAA-Fwd & GCCCTCGGTGAGGATCGCTGCGGCT \\
\hline hCNGB-AAAA-Rev & CCGGGATCAGGGCCTGCAGCCGCAG \\
\hline mB1-535-Not-R & AGAGTCGCGGCCGCTTCAGGGGCCACTATCAGCATCCG \\
\hline mB1-358-Not-R & AGAGTCGCGGCCGCTTCATATCTCCACTATGGCCTCAC \\
\hline myc-mCNGB1-F & CAAAAACTCATCTCAGAAGAGGATCTGATGTTGGGCTGGGTCCAAAG \\
\hline myc-hCNGB1-F & CAAAAACTCATCTCAGAAGAGGATCTGTTGGGCTGGGTCCAGAGGGT \\
\hline myc-mB1-359-F & CAAAAACTCATCTCAGAAGAGGATCTGCCCAGGGAGCTGACGAAGAT \\
\hline Myc-hCNGB1-344-457-F & CAAAAACTCATCTCAGAAGAGGATCTGATGCCCAGAGAGCTGTCC \\
\hline
\end{tabular}




\section{References}

Amaya E, Kroll KL (1999) A method for generating transgenic frog embryos. Methods Mol Biol 97:393-414.

Ardell MD, Bedsole DL, Schoborg RV, Pittler SJ (2000) Genomic organization of the human rod photoreceptor cGMP-gated cation channel beta-subunit gene. Gene 245:311-318.

Ardell MD, Makhija AK, Oliveira L, Miniou P, Viegas-Péquignot E, Pittler SJ (1995) cDNA, gene structure, and chromosomal localization of human GAR1 (CNCG3L), a homolog of the third subunit of bovine photoreceptor cGMP-gated channel. Genomics 28:32-38.

Ardell MD, Aragon I, Oliveira L, Porche GE, Burke E, Pittler SJ (1996) The beta subunit of human rod photoreceptor cGMP-gated cation channel is generated from a complex transcription unit. FEBS Lett 389:213-218.

Baker SA, Haeri M, Yoo P, Gospe SM, Skiba NP, Knox BE, Arshavsky VY (2008) The outer segment serves as a default destination for the trafficking of membrane proteins in photoreceptors. J Cell Biol 183:485-498.

Batni S, Mani SS, Schlueter C, Ji M, Knox BE (2000) Xenopus rod photoreceptor: model for expression of retinal genes. Methods Enzymol 316:50-64.

Bauer PJ (1988) Evidence for two functionally different membrane fractions in bovine retinal rod outer segments. J Physiol 401:309-327.

Chen TY, Peng YW, Dhallan RS, Ahamed B, Reed RR, Yau KW (1993) A new subunit of the cyclic nucleotide-gated cation channel in retinal rods. Nature 362:764-767.

Colville CA, Molday RS (1996) Primary structure and expression of the human beta-subunit and related proteins of the rod photoreceptor cGMP-gated channel. J Biol Chem 271:3296832974.

Conley SM, Ding XQ, Naash MI (2010) RDS in cones does not interact with the beta subunit of the cyclic nucleotide gated channel. Adv Exp Med Biol 664:63-70.

Conley SM, Stuck MW, Watson JN, Zulliger R, Burnett JL, Naash MI (2019) Prph2 initiates outer segment morphogenesis but maturation requires Prph2/Rom1 oligomerization. Hum Mol Genet 28:459-475.

Connell GJ, Molday RS (1990) Molecular cloning, primary structure, and orientation of the vertebrate photoreceptor cell protein peripherin in the rod outer segment disk membrane. Biochemistry 29:4691-4698.

DeRamus ML, Stacks DA, Zhang Y, Huisingh CE, McGwin G, Pittler SJ (2017) GARP2 accelerates retinal degeneration in rod CGMP-gated cation channel $\beta$-subunit knockout mice. Sci Rep 7:42545.

Deretic D, Papermaster DS (1991) Polarized sorting of rhodopsin on post-Golgi membranes in frog retinal photoreceptor cells. J Cell Biol 113:1281-1293.

Deretic D, Schmerl S, Hargrave PA, Arendt A, McDowell JH (1998) Regulation of sorting and post-Golgi trafficking of rhodopsin by its C-terminal sequence QVS(A)PA. Proc Natl Acad Sci 95:10620-10625.

Goldberg AF, Moritz OL, Williams DS (2016) Molecular basis for photoreceptor outer segment architecture. Prog Retin Eye Res 55:52-81.

Gospe SM, Baker SA, Kessler C, Brucato MF, Winter JR, Burns ME, Arshavsky VY (2011) Membrane attachment is key to protecting transducin GTPase-activating complex from intracellular proteolysis in photoreceptors. J Neurosci 31:14660-14668.

Grunwald ME, Yu WP, Yu HH, Yau KW (1998) Identification of a domain on the beta-subunit of the rod cGMP-gated cation channel that mediates inhibition by calcium-calmodulin. J Biol Chem 273:9148-9157.

Hu G, Wensel TG (2002) R9AP, a membrane anchor for the photoreceptor GTPase accelerating protein, RGS9-1. Proc Natl Acad Sci 99:9755-9760. 
Hüttl S, Michalakis S, Seeliger M, Luo DG, Acar N, Geiger H, Hudl K, Mader R, Haverkamp S, Moser M, Pfeifer A, Gerstner A, Yau KW, Biel M (2005) Impaired channel targeting and retinal degeneration in mice lacking the cyclic nucleotide-gated channel subunit CNGB1. J Neurosci 25:130-138.

Illing M, Molday LL, Molday RS (1997) The 220-kDa rim protein of retinal rod outer segments is a member of the ABC transporter superfamily. J Biol Chem 272:10303-10310.

Jenkins PM, Zhang L, Thomas G, Martens JR (2009) PACS-1 mediates phosphorylationdependent ciliary trafficking of the cyclic-nucleotide-gated channel in olfactory sensory neurons. J Neurosci 29:10541-10551.

Jenkins PM, Hurd TW, Zhang L, McEwen DP, Brown RL, Margolis B, Verhey KJ, Martens JR (2006) Ciliary targeting of olfactory CNG channels requires the CNGB1b subunit and the kinesin-2 motor protein, KIF17. Curr Biol 16:1211-1216.

Kaupp UB, Niidome T, Tanabe T, Terada S, Bönigk W, Stühmer W, Cook NJ, Kangawa K, Matsuo $\mathrm{H}$, Hirose $\mathrm{T}$ (1989) Primary structure and functional expression from complementary DNA of the rod photoreceptor cyclic GMP-gated channel. Nature 342:762-766.

Keresztes G, Mutai H, Hibino H, Hudspeth AJ, Heller S (2003) Expression patterns of the RGS91 anchoring protein R9AP in the chicken and mouse suggest multiple roles in the nervous system. Mol Cell Neurosci 24:687-695.

Keresztes G, Martemyanov KA, Krispel CM, Mutai H, Yoo PJ, Maison SF, Burns ME, Arshavsky VY, Heller S (2004) Absence of the RGS9.Gbeta5 GTPase-activating complex in photoreceptors of the R9AP knockout mouse. J Biol Chem 279:1581-1584.

Kizhatil K, Baker SA, Arshavsky VY, Bennett V (2009) Ankyrin-G promotes cyclic nucleotidegated channel transport to rod photoreceptor sensory cilia. Science 323:1614-1617.

Krispel CM, Chen D, Melling N, Chen YJ, Martemyanov KA, Quillinan N, Arshavsky VY, Wensel TG, Chen CK, Burns ME (2006) RGS expression rate-limits recovery of rod photoresponses. Neuron 51:409-416.

Kroll KL, Amaya E (1996) Transgenic Xenopus embryos from sperm nuclear transplantations reveal FGF signaling requirements during gastrulation. Development 122:3173-3183.

Luo W, Marsh-Armstrong N, Rattner A, Nathans J (2004) An outer segment localization signal at the $C$ terminus of the photoreceptor-specific retinol dehydrogenase. J Neurosci 24:26232632.

Milstein ML, Kimler VA, Ghatak C, Ladokhin AS, Goldberg AFX (2017) An inducible amphipathic helix within the intrinsically disordered $C$ terminus can participate in membrane curvature generation by peripherin-2/rds. J Biol Chem 292:7850-7865.

Molday RS, Molday LL (1987) Differences in the protein composition of bovine retinal rod outer segment disk and plasma membranes isolated by a ricin-gold-dextran density perturbation method. J Cell Biol 105:2589-2601.

Molday RS, Molday LL (1998) Molecular properties of the cGMP-gated channel of rod photoreceptors. Vision Res 38:1315-1323.

Molday RS, Molday LL, Dosé A, Clark-Lewis I, Illing M, Cook NJ, Eismann E, Kaupp UB (1991) The cGMP-gated channel of the rod photoreceptor cell characterization and orientation of the amino terminus. J Biol Chem 266:21917-21922.

Murray AR, Fliesler SJ, Al-Ubaidi MR (2009) Rhodopsin: the functional significance of asn-linked glycosylation and other post-translational modifications. Ophthalmic Genet 30:109-120.

Najafi M, Maza NA, Calvert PD (2012) Steric volume exclusion sets soluble protein concentrations in photoreceptor sensory cilia. Proc Natl Acad Sci 109:203-208.

Navarro Negredo P, Edgar JR, Wrobel AG, Zaccai NR, Antrobus R, Owen DJ, Robinson MS (2017) Contribution of the clathrin adaptor AP-1 subunit $\mu 1$ to acidic cluster protein sorting. J Cell Biol 216:2927-2943.

Nemet I, Tian G, Imanishi Y (2014) Organization of cGMP sensing structures on the rod photoreceptor outer segment plasma membrane. Channels 8:528-535. 
Otsu W, Hsu YC, Chuang JZ, Sung CH (2019) The Late Endosomal Pathway Regulates the Ciliary Targeting of Tetraspanin Protein Peripherin 2. J Neurosci 39:3376-3393.

Pearring JN, Salinas RY, Baker SA, Arshavsky VY (2013) Protein sorting, targeting and trafficking in photoreceptor cells. Prog Retin Eye Res 36:24-51.

Pearring JN, Spencer WJ, Lieu EC, Arshavsky VY (2015) Guanylate cyclase 1 relies on rhodopsin for intracellular stability and ciliary trafficking. Elife 4:e12058.

Pearring JN, Lieu EC, Winter JR, Baker SA, Arshavsky VY (2014) R9AP targeting to rod outer segments is independent of rhodopsin and is guided by the SNARE homology domain. Mol Biol Cell 25:2644-2649.

Poetsch A, Molday LL, Molday RS (2001) The cGMP-gated channel and related glutamic acidrich proteins interact with peripherin-2 at the rim region of rod photoreceptor disc membranes. J Biol Chem 276:48009-48016.

Ramamurthy V, Jolicoeur C, Koutroumbas D, Muhlhans J, Le YZ, Hauswirth WW, Giessl A, Cayouette M (2014) Numb regulates the polarized delivery of cyclic nucleotide-gated ion channels in rod photoreceptor cilia. J Neurosci 34:13976-13987.

Reid DM, Friedel U, Molday RS, Cook NJ (1990) Identification of the sodium-calcium exchanger as the major ricin-binding glycoprotein of bovine rod outer segments and its localization to the plasma membrane. Biochemistry 29:1601-1607.

Ritter LM, Khattree N, Tam B, Moritz OL, Schmitz F, Goldberg AF (2011) In situ visualization of protein interactions in sensory neurons: glutamic acid-rich proteins (GARPs) play differential roles for photoreceptor outer segment scaffolding. J Neurosci 31:11231-11243.

Salinas RY, Baker SA, Gospe SM, Arshavsky VY (2013) A single valine residue plays an essential role in peripherin/rds targeting to photoreceptor outer segments. PLoS One 8:e54292.

Skiba NP, Spencer WJ, Salinas RY, Lieu EC, Thompson JW, Arshavsky VY (2013) Proteomic identification of unique photoreceptor disc components reveals the presence of PRCD, a protein linked to retinal degeneration. J Proteome Res 12:3010-3018.

Spencer WJ, Lewis TR, Pearring JN, Arshavsky VY (2020) Photoreceptor Discs: Built Like Ectosomes. Trends Cell Biol S0962-8924:30165-30163.

Spencer WJ, Pearring JN, Salinas RY, Loiselle DR, Skiba NP, Arshavsky VY (2016) Progressive Rod-Cone Degeneration (PRCD) Protein Requires N-Terminal S-Acylation and Rhodopsin Binding for Photoreceptor Outer Segment Localization and Maintaining Intracellular Stability. Biochemistry 55:5028-5037.

Spencer WJ, Lewis TR, Phan S, Cady MA, Serebrovskaya EO, Schneider NF, Kim KY, Cameron LA, Skiba NP, Ellisman MH, Arshavsky VY (2019) Photoreceptor disc membranes are formed through an Arp2/3-dependent lamellipodium-like mechanism. Proc Natl Acad Sci 116(52):27043-27052.

Sugimoto Y, Yatsunami K, Tsujimoto M, Khorana HG, Ichikawa A (1991) The amino acid sequence of a glutamic acid-rich protein from bovine retina as deduced from the cDNA sequence. Proc Natl Acad Sci 88:3116-3119.

Sung CH, Makino C, Baylor D, Nathans J (1994) A rhodopsin gene mutation responsible for autosomal dominant retinitis pigmentosa results in a protein that is defective in localization to the photoreceptor outer segment. J Neurosci 14:5818-5833.

Tam BM, Moritz OL, Papermaster DS (2004) The C terminus of peripherin/rds participates in rod outer segment targeting and alignment of disk incisures. Mol Biol Cell 15:2027-2037.

Tam BM, Moritz OL, Hurd LB, Papermaster DS (2000) Identification of an outer segment targeting signal in the $\mathrm{COOH}$ terminus of rhodopsin using transgenic Xenopus laevis. $\mathrm{J}$ Cell Biol 151:1369-1380.

Tian G, Ropelewski P, Nemet I, Lee R, Lodowski KH, Imanishi Y (2014) An unconventional secretory pathway mediates the cilia targeting of peripherin/rds. J Neurosci 34:992-1006. 
Trudeau MC, Zagotta WN (2002) An intersubunit interaction regulates trafficking of rod cyclic nucleotide-gated channels and is disrupted in an inherited form of blindness. Neuron 34:197-207.

Tsybovsky Y, Wang B, Quazi F, Molday RS, Palczewski K (2011) Posttranslational modifications of the photoreceptor-specific ABC transporter ABCA4. Biochemistry 50:6855-6866.

Weitz D, Ficek N, Kremmer E, Bauer PJ, Kaupp UB (2002) Subunit stoichiometry of the CNG channel of rod photoreceptors. Neuron 36:881-889.

Weitz D, Zoche M, Müller F, Beyermann M, Körschen HG, Kaupp UB, Koch KW (1998) Calmodulin controls the rod photoreceptor CNG channel through an unconventional binding site in the N-terminus of the beta-subunit. EMBO J 17:2273-2284.

Whitaker SL, Knox BE (2004) Conserved transcriptional activators of the Xenopus rhodopsin gene. J Biol Chem 279:49010-49018.

Zhang Y, Molday LL, Molday RS, Sarfare SS, Woodruff ML, Fain GL, Kraft TW, Pittler SJ (2009) Knockout of GARPs and the $\beta$-subunit of the rod cGMP-gated channel disrupts disk morphogenesis and rod outer segment structural integrity. J Cell Sci 122:1192-1200.

Zheng J, Trudeau MC, Zagotta WN (2002) Rod cyclic nucleotide-gated channels have a stoichiometry of three CNGA1 subunits and one CNGB1 subunit. Neuron 36:891-896.

Zhong H, Molday LL, Molday RS, Yau KW (2002) The heteromeric cyclic nucleotide-gated channel adopts a 3A:1B stoichiometry. Nature 420:193-198.

Zulliger R, Conley SM, Mwoyosvi ML, Stuck MW, Azadi S, Naash MI (2015) SNAREs Interact with Retinal Degeneration Slow and Rod Outer Segment Membrane Protein-1 during Conventional and Unconventional Outer Segment Targeting. PLoS One 10:e0138508. 